\title{
Associate Professor Khim Nian Sin Fai Lam (1949-2018)
}

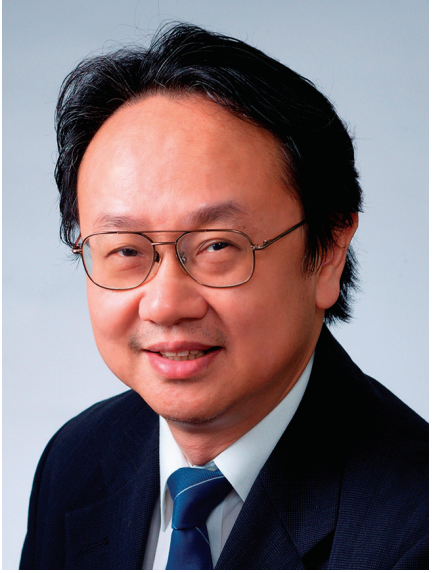

Associate Professor Khim Nian Sin Fai Lam passed away peacefully at home on 29 April 2018 at the age of 69. Born in Mauritius, he graduated as a doctor from Queen's University, Belfast, United Kingdom, in 1974. He subsequently obtained further qualifications and trained in both internal and respiratory medicine. He came to Singapore in 1983 and spent most of his working life at Alexandra Hospital (AH) and Khoo Teck Puat Hospital (KTPH). An exemplary foreign-talent recruit for Singapore, he excelled as a clinician, teacher, boss, mentor and distinguished colleague in the medical fraternity.

Khim, as he is fondly known by those of us close to him, was a true gentleman with a very infectious smile and affable character. He had a knack for dealing with all types of personalities. He was an effective counsellor and a mediator who often convinced us to use a better and yet different way of communicating information or sorting out an issue in adversity with his trademark phrase "Take it easy". Khim taught, mentored and trained generations of medical students and junior doctors (including myself) who benefitted from his astute clinical acumen, methodical approach, and reassuring and encouraging style. His clinical problemsolving and reasoning skills were remarkable. Nonetheless, this unassuming clinician, who would think, brood and tear his hair out over diagnostic difficulties, never hesitated to ask his junior for a second opinion whenever he felt it would benefit the patient. His wisdom combined with his wit and humour have inspired generations of disciples. An extremely hardworking physician, he was always available for and supportive of his juniors. Word spread in the department that, "If you cannot get anyone for help, call Prof Sin; he will come and respond to a call for help whether or not it is his patient, whether or not he is on duty."

Despite having one of the highest out- and inpatient clinical loads in the hospital, and other responsibilities, Prof Sin always managed to treat his patients with quality, compassion and dignity, the same qualities he wanted for himself in his illness. He had an incredible rapport with patients, who adored him many walked the corridors of KTPH drenched in emotion when he was ill and they realised they could not consult him any more. When one of his patients' relatives threatened to assault him, much as he was upset, Prof Sin absolutely refused to take any action, but instead said philosophically, "The doctor-patient relationship was lost, and the patient should have the benefit of another independent doctor." As a close friend, Khim instilled in me that I had a duty to stop him whenever I felt he should not do medicine. He unreservedly emphasised that the true interest of the patient had to come above the interest of our friendship. For himself, he did not want care that was futile or compromised quality of life - as he would have wanted for his patients.

His academic pursuits were impressively congruent with his clinical skills. He had contributed numerous articles on a plethora of topics in internal medicine. These included wheeze in pollen-sensitive patients, asthma, hypercholesterolaemia, endocarditis, schistosomiasis, lactic acidosis, pain in terminal care, myocardial infarction, diabetes, malignant hypertension, amyloidosis, tetanus, mercury poisoning, tuberculosis, coarctation, osteomyelitis and mediastinal goitre. He was the principal author of a book entitled X-Ray Diagnosis: A Physician's Approach. One legendary, thought-provoking - and very popular - contribution of Prof Sin was his regular email circulation of articles of interest to the medical community with his personal comments, philosophy, quotes and quips on topics ranging from music or art in medicine to over-investigations, la maladie du grand print out ('the disease of the big printout', referring to patients who are armed with excessive information), the residency programme and the reliability of clinical signs. Khim's fluency and articulateness in both French and English, together with his Mauritian accent, made his quips unique and memorable.

Prof Sin was the first Associate Dean of AH (2001-2013), as well as the first Education Director (2014-2016) and Head, Department of Medicine (2003-2011), of KTPH. He contributed to numerous hospital, national, academic and professional organisations. At the same time, he was always more concerned with getting his juniors promoted than achieving personal advancement. Much as many of us felt that he deserved it more than those he supported, he always declined with a smile and a "No, no"; a true reflection of a magnanimous, humble and gracious boss who thrived on his juniors' success.

There was no doubt that Khim was a loving family man who treasured his family. Although he was a very private man, he could never hide his joys or anxieties about his family. He was extremely happy when his children were very successful in their respective careers and when they got married, and anxious when his daughters were to deliver his grandchildren.

Khim affected all our lives in many ways. His wife, three children (and their respective spouses) and grandchildren lost a loving husband, father and doting grandfather. His colleagues lost a great friend, confidant and mentor. His students lost a great inspirational teacher and the medical community lost an astute and caring physician and role model. He remains a pillar of $\mathrm{AH}$ and $\mathrm{KTPH}$ that will stand forever. May he rest in peace, as we live in fond memories and reflections of his contributions over a lifetime. We have all benefitted from the wisdom, humour, wit and magnanimity of a good man who led a great life in his own quiet and humble way.

Prof C Rajasoorya 